\title{
Valuing of Social Impact Assessment: building sound relations towards mitigating project delays
}

\author{
Xolani Ngonini \\ Trans-Caledon Tunnel Authority, Centurion, South Africa
}

\begin{abstract}
This paper explores how state-owned entity in South Africa learned from an ineffective conceptualisation of the notion of the 'license to operate' from a project that encountered over 300days of work stoppages, how it has utilised such lessons to foster sound community facilitation before project implementation. In the recent past, the interface between megaprojects and projectedaffected communities has evolved from the traditional approach to incorporate innovative methods. These innovative approaches acknowledged that measuring project impact requires the entity to not focus on financial and economic value in an isolated way. Instead, it must make assessments across environmental, social, and financial dimensions, ensuring that the processes and practices do not favour a narrow emphasis on biophysical impacts. Research for the paper shows that social impacts span a range that includes health and well-being, liveability, economic, cultural, family and community, political/legal, and gender, and must be experienced or felt incorporeal or perceptual terms. The assessment sought to reflect on the implementation and outcomes of Social Impact Assessment (analysing, monitoring and management) interfaces with project-affected communities or interested and affected parties. The paper challenges common perceptions of "stakeholder engagement and facilitation" by focusing on the socio-economic context of the project's location, role players and their agendas, histories of development or lack thereof and highlights the importance of political trust (cultural capital). Commonly held views of the processes concerning stakeholders' understanding of social impacts are limited to an assessment of their recognition of the value of participation. However, there is an emergent drive towards co-creational processes and influences on how community groups achieve a collective level understanding of complex decisions and impacts. The import of this paper the body of knowledge resides in the transfer of lessons from one project to another, to minimise instances of community protests and improve stakeholder engagement. interviews were conducted with community leaders, business owners, affected households and many other stakeholders.
\end{abstract}

Keywords: social impact assessment, land ownership regimes, TCTA, project subcontractors or local business owners, and South Africa 